\title{
How to counter the ten myths about work addiction?: Three postulates for future research
}

\author{
Commentary on: Ten myths about work addiction (Griffiths et al., 2018) \\ DIANA MALINOWSKA* \\ Institute of Psychology, Jagiellonian University, Kraków, Poland
}

(Received: July 18, 2018; revised manuscript received: November 20, 2018; accepted: November 22, 2018)

\begin{abstract}
Background and aim: Referring to Ten myths about work addiction reviewed by Griffiths, Demetrovics, and Atroszko in the Journal of Behavioral Addiction, three postulates were proposed to apply in future research on work addiction: (a) the clinical psychology perspective, (b) the systems approach, and (c) diversified and adequate methodologies. Methods: In a narrative review, using theoretical assumptions and empirical data, postulates were discussed against myths. Results: The opportunities offered by the perspectives and new insights related to myths were presented. Conclusion: It appears that the three postulates may contribute to theoretical and methodological progress in future research on work addiction.
\end{abstract}

Keywords: behavioral addiction, work addiction, workaholism

\section{INTRODUCTION}

The ancient myth of Addictus presents a slave whose master set him free, but the slave was so used to his chains that when his master freed him, the slave wandered the land with his chains still intact. Reflecting upon the 10 myths about work addiction, Griffiths, Demetrovics, and Atroszko (2018) initiated a necessary scientific debate on what we know and do not know about people who are addicted. Although scientists present mostly numbers, behind these numbers lies the drama of people who are slaves to their jobs. In this article, I advocate the primacy of theory and method in stimulating progress in research on work addiction and consequently in providing evidence-based knowledge to practitioners who work with addicted individuals and their organizations. Specifically, I focus on applying the following in research on work addiction: (a) the clinical psychology perspective, (b), the systems approach, and (c) diversified methodology related to the underlying theory.

\section{THE CLINICAL PSYCHOLOGY PERSPECTIVE}

Most researchers would agree that solely relying on work hours ("Myth 9") to represent work addiction would be misleading. What I see as more fundamental and hindering of progress in the study of work addiction is the lack of agreement on what it actually is and consequently how it should be measured. Occupational health psychology researchers define "workaholism" as an addiction, but they also adopt the definition of Schaufeli, Taris, and Bakker (2008), who state that it is "the tendency to work excessively hard in a compulsive way" (p. 204). This definition ignores several clinical classification criteria and does not consider temporal and contextual manifestations of addiction (Griffiths, 2005, 2011). Moreover, the available assessment tools are only vaguely embedded within the authors' different theoretical frameworks (Andreassen, 2014). Consequently, theoretical heterogeneity leads to diverse research results on work addiction, which show, for instance, that the construct measured as an addiction is positively correlated with subjective ill health, whereas these associations are non-significant when measured as a behavioral tendency (Chodkiewicz \& Hauk, 2012). The clinical psychology perspective is undeniably needed to appropriately operationalize and measure work addiction, set norms, and determine appropriate cut scores for those addicted and non-addicted to work.

To properly address the difference between work addiction and workaholism ("Myth 4"), an important remark comes from the history of alcohol addiction. The turning point was the publication of DSM-III (American Psychiatric Association [APA], 1980), in which the term "alcoholism" was rejected, and differentiation between alcohol abuse and alcohol dependence was introduced (Babor, 1992; Nathan, 1991; Schuckit, 1994). The first category was used so as not

\footnotetext{
* Corresponding address: Diana Malinowska; Institute of Psychology, Jagiellonian University, Ingardena 6, Kraków 30 060, Poland; Phone: +48 1266324 13; Fax: +48 1266324 17; E-mail: d.malinowska@uj.edu.pl
}

This is an open-access article distributed under the terms of the Creative Commons Attribution-NonCommercial 4.0 International License, which permits unrestricted use, distribution, and reproduction in any medium for non-commercial purposes, provided the original author and source are credited, a link to the CC License is provided, and changes - if any - are indicated. 
to miss the health consequences of drinking, even if addictive symptoms (tolerance and withdrawal) are absent (Hasin, Grant, \& Endicott, 1990). DSM-5 (APA, 2013) integrates these two categories into a single disorder called alcohol-use disorder, with mild, moderate, and severe subclassifications based on the number of criteria met. As a consequence of terminological unification, "alcoholism" is now conceived by researchers and the lay public exclusively as a social problem.

An important insight into "Myth 10" (Workaholism is an example of overpathologizing everyday behavior and it will never be classed as a mental disorder in the DSM) that also comes from the clinical perspective is the boundary between the norm and pathology. Griffith's (2005) metaphor that "healthy behaviours add to life whereas addictions take away from it" (p. 98) is in line with contemporary changes in the classification of mental disorders that favor the harmfulness of "otherness" (Habrat, 2018). For instance, pathological gambling, which is included in DSM-5 (APA, 2013), has documented negative impacts on gamblers (e.g., jeopardizing or losing significant relationships or career opportunities). The results on work addiction have shown that it is related to many negative outcomes (Clark, Michel, Zhdanova, Pui, \& Baltes, 2016); however, more specific studies are needed to determine "clinically significant distress or impairment in social, occupational, or other areas of functioning" (APA, 2013, p. 21).

In an attempt to further our understanding of the unique aspects of work addiction ("Myth 2"), it is necessary to consider that the co-occurrence of other addictions (or disorders) is strengthened in the clinical psychology perspective. For instance, based on clinical observations, Durand-Moreau, Le Deun, Lodde, and Dewitte (2018) noticed that work-addicted people might have problems with tobacco consumption and alcohol or eating disorders. Thus, substance-related and behavioral addictive disorders should be assessed when work addiction is suspected. An important topic for future research that comes from comorbidity studies is that addictions are accompanied by disorganized emotional regulation (Kuhn \& Demetrovics, 2010). Thus, the role of emotions in work addiction should also be studied.

\section{THE SYSTEMS APPROACH}

The quotation below, which presents the core assumption of the modern system perspective, demonstrates the complexity of the components in the analysis of individuals and gives sound arguments to counter "Myth 5" (Work addiction occurs as a consequence of individual personality factors): "An individual develops and functions psychologically as an integrated organism. Maturational, experiential and cultural contributions are fused in this ontogeny" (Magnusson \& Cairns, 1996, p. 12).

In fact, globalized post-industrial society has led to the normalization of intensive work (Worrall, Mather, \& Cooper, 2016) and has thus created environmental affordances (Gibson, 1975) to display individual predispositions to work addiction. For instance, Mazzetti, Schaufeli, and Guglielmi (2014) found that conscientiousness and self-efficacy were related to work addiction, but only in interaction with the presence of a climate of overwork. For individuals, there are also emotional consequences of globalization, which influence their work attitudes and workplace behaviors; some examples are self-doubt and/or anxious preoccupation with matters of professional standing (Elliot \& Lemert, 2006; Malinowska, Trzebińska, Tokarz, \& Kirkcaldy, 2013).

We cannot deny that socioeconomic and cultural differences related to the East-West dichotomy may also influence the level of work addiction and work engagement, as shown in the study of $\mathrm{Hu}$ et al. (2014). In addition, the Japanese corporate culture malpractice that is expected to lead to "karoshi" is known as "sabisu zangyo," which means voluntary overtime. Overtime is supposed to be for unanticipated occasions in Western Europe, but in Japan, where the social value system exhorts "ganbaru" (to suffer in silence and to endure difficulties), it has become an expected part of daily duties that nobody can refuse (Kirrane, Breen, \& O'Connor, 2018).

It is perhaps worth pointing out Weber's (2005) notion of "the influences of religious ideas on the development of economic spirit, or the ethos of an economic system" (p. 34). It seems interesting to consider that some differences in work addiction (and its associations with other variables) between countries may be found in local religious systems. In the study of Atroszko, Andreassen, Griffiths, and Palleasen (2016), who used Polish and Norwegian samples, it was found that neuroticism was only related to work addiction in Norway, where most people belong to the Evangelical Lutheran Church, whereas Poland is Roman Catholic.

Studying national cultures in the analysis of work addiction would give a solid basis for arguing against the notion that it is a new behavioral addiction ("Myth 1"). It is essential to emphasize that when the term "work addiction" first appeared in an American journal (Oates, 1968), it manifested itself in Japan in the late 1960s as a social phenomenon of death from work - "karoshi" (Sugisawa \& Uehata, 1998).

The systems approach would also provide strong arguments against "Myth 3" (There are only psychosocial consequences of work addiction). More studies are needed on the perspectives of partners and children of the work-addicted, who are part of dysfunctional family systems and their dynamics (Bakker, Demerouti, \& Burke, 2009; Chamberlin \& Zhang, 2009; L'Abate \& L'Abate, 1981; Robinson \& Kelley, 1998). Beyond this, we have to analyze more deeply the diverse long-term consequences of work addiction and look into its impact on co-workers and organizations. For instance, Shimazu, Schaufeli, Kamiyama, and Kamakami (2015) found in their 2-year follow-up replication that work addiction did not lead to impaired job performance. However, we should be aware that measures of studying change must be sensitive to appropriate forms of change over time.

\section{DIVERSIFIED AND ADEQUATE METHODOLOGIES}

The postulate of using diversified and adequate methodologies can be used to push work addiction researchers into the longitudinal realm, which offers more ways of studying 
change and seeing if some types of work addiction are positive in the long-term ("Myth 7"). An even more compelling reason to use a longitudinal design is the opportunity it presents not only to analyze the stages of work addiction and its development over time, but also to disentangle the psychological mechanism through which people progress from excessive work to addiction.

Importantly, the diary method enables more to be learnt about changing states over time and about how specific states and behaviors translate into other states and behaviors within relatively short periods of time (Reis \& Gable, 2000). As stated in "The clinical psychology perspective" section, when studies on the role of emotions in work addiction are needed, this is an excellent method to capture changes in and correlates of individuals' moods and emotions, with limited retrospection artifacts and biases.

Other important questions that should be addressed with the use of an adequate methodology are when the development of work addiction begins (see "Myth 6": Work addiction only occurs in adulthood) and how it should be measured. Importantly, case studies or other qualitative techniques used in the approaches of clinical psychology and systems could constitute raw preliminary data for further quantitative studies. For example, in a qualitative investigation of the origins of excessive work behavior, a participant invokes his early age experience of hard work (Kirrane et al., 2018): "So even from an early age I was working. My father was a holy terror for work, work, work, work' (p. 243). In this study, it was found that educational practices were construed by participants of the study as factors that influenced work practices, thus providing insights into "Myth 5" (Work addiction occurs as a consequence of individual personality factors).

Based on the systems approach, future research should expand beyond the self-reports of the work-addicted. Incorporating multisource data from partners, children, coworkers, and supervisors help address several research questions about the psychosocial consequences for these groups. For instance, the work-addicted partners report being less supported by them, which results in reduced relationship satisfaction (Bakker et al., 2009).

Finally, it is worth noting that both methodological approaches and analysis offer sources of evidence-based knowledge to debate, for example, the claim that work addiction is a transient behavioral pattern related to situational factors ("Myth 8"). As noted earlier, the systems approach recognizes the contextual nature of work addiction and its interaction with personal antecedents. Thus, multilevel models currently present an important means of testing such speculations. To illustrate, a competitive climate was more strongly related to work addiction under conditions of high future orientation and high calling (Keller, Spurk, Baumeler, \& Hirschi, 2016). Moreover, questions about individual differences in changes and factors predicting such individual differences may be better answered through multilevel research, particularly through the use of random coefficient models (Beliese \& Ployhart, 2002). Such a perspective also serves the very practical need to acknowledge the interdependence between the intra- and interlevel processes of change when designing interventions (Raudenbush \& Bryk, 2002).

\section{CONCLUSIONS}

In this commentary, I advocate including the following in future research: (a) the clinical psychology perspective, which could mostly contribute to the definition of work addiction and its pathological nature; (b) the systems approach, which sheds light on the antecedents and consequences of work addiction; and (c) diversified methodologies that should not be based on convenience but on the underlying theories and research questions. As quoted by Ployhart (2008), "When theory, methods, and statistics fit like pieces of a puzzle, the gestalt becomes visible in ways not possible from the individual pieces (...)" (p. 18). It appears that future research on work addiction using these three postulates may counter the 10 myths, or even more.

Funding sources: No financial support was received for this study.

Author's contribution: DM contributed to study concept and design, analysis and interpretation of data, and writing of the manuscript. The author had full access to all data in the study and took responsibility for the integrity of the data and the accuracy of the data analysis.

Conflict of interest: The author declares no conflict of interest.

\section{REFERENCES}

American Psychiatric Association [APA]. (1980). Diagnostic and statistical manual of mental disorders (3rd ed.). Washington, DC: American Psychiatric Association.

American Psychiatric Association [APA]. (2013). Diagnostic and statistical manual of mental disorders (5th ed.). Arlington, VA: American Psychiatric Association.

Andreassen, C. S. (2014). Workaholism: An overview and current status of the research. Journal of Behavioural Addictions, 3(1), 1-11. doi:10.1556/JBA.2.2013.017

Atroszko, P. A., Andreassen, C.S., Griffiths, M. D., \& Palleasen, S. (2016). Study addiction: A cross-cultural longitudinal study examining temporal stability and predictors of its changes. Journal of Behavioural Addictions, 5(2), 357-362. doi:10.1556/ 2006.5.2016.024

Babor, T. F. (1992). Substance-related problems in the context of international classificatory systems. In M. Lader, G. Edwards, \& D. C. Drummond (Eds.), The nature of alcohol and drug related problems. New York, NY: Oxford University Press.

Bakker, A. B., Demerouti, E., \& Burke, R. (2009). Workaholism and relationship quality: A spillover-crossover perspective. Journal of Occupational Health Psychology, 14(1), 23-33. doi:10.1037/a0013290

Beliese, P. D., \& Ployhart, R. E. (2002). Growth modeling using random coefficient models: Model building, testing and illustrations. Organizational Research Methods, 5(4), 362-387. doi:10.1177/109442802237116 
Chamberlin, C. M., \& Zhang, N. J. (2009). Workaholism, health and self-acceptance. Journal of Counseling and Development, 87(2), 159-169. doi:10.1002/j.1556-6678.2009.tb00563.x

Chodkiewicz, J., \& Hauk, M. (2012). The relationship between workaholism defined as an addiction and a behavioral tendency and work-family conflict. Medycyna Pracy, 63(2), 199-209. doi:10.2478/s13382-013-0087-1

Clark, M. A., Michel, J. S., Zhdanova, L., Pui, S. Y., \& Baltes, B. B. (2016). All work and no play? A meta-analytic examination of the correlates and outcomes of workaholism. Journal of Management, 42(7), 1836-1873. doi:10.1177/ 0149206314522301

Durand-Moreau, Q., Le Deun, C., Lodde, B., \& Dewitte, J.-D. (2018). The framework of clinical occupational medicine to provide new insight for workaholism. Industrial Health, 56(5), 441-451. doi:10.2486/indhealth.2018-0021

Elliot, A., \& Lemert, Ch. (2006). The new individualism. The emotional cost of globalization. London, UK: Routledge.

Gibson, J. J. (1975). Affordances and behavior. In E. S. Reed \& R. Jones (Eds.), Reasons for realism: Selected essays of James J. Gibson (1st ed., pp. 410-411). Hillsdale, NJ: Lawrence Erlbaum Associates.

Griffiths, M. D. (2005). A "components" model of addiction within a biopsychosocial framework. Journal of Substance Use, 10(4), 191-197. doi:10.1080/14659890500114359

Griffiths, M. D. (2011). Workaholism: A 21st century addiction. The Psychologist: Bulletin of the British Psychological Society, 24, 740-744. Retrieved from https://thepsychologist.bps.org. uk/getfile/1093

Griffiths, M. D., Demetrovics, Z., \& Atroszko, P. A. (2018). Ten myths about work addiction. Journal of Behavioral Addiction, 7, 1-13. doi:10.1556/2006.7.2018.05

Habrat, B. (Ed.) (2018). Zaburzenia uprawiania hazardu i inne tak zwane natogi behawioralne [Pathological gambling and other so called behavioural addictions]. Warsaw, Poland: Instytut Psychiatrii i Neurologii.

Hasin, D. S., Grant, B., \& Endicott, J. (1990). The natural history of alcohol abuse: Implications for definitions of alcohol use disorders. American Journal of Psychiatry, 147(1), 1537-1541. doi:10.1176/ajp.147.11.1537

Hu, Q., Schaufeli, W. B., Taris, T., Hessen, D. J., Hakanen, J., Salanova, M., \& Shimazu, A. (2014). "East is east and west is west and never the twain shall meet:" Work engagement and workaholism across Eastern and Western culture. Journal of Behavioral and Social Sciences, 1(1), 6-24. Retrieved from https://www.wilmarschaufeli.nl/publications/Schaufeli/ 427.pdf

Keller, A. C., Spurk, D., Baumeler, F., \& Hirschi, A. (2016). Competitive climate and workaholism: Negative sides of future orientation and calling. Personality and Individual Differences, 96, 122-126. doi:10.1016/j.paid.2016.02.061

Kirrane, M., Breen, M., \& O'Connor, C. (2018). A qualitative investigation of the origins of excessive work behaviour. Journal of Occupational and Organizational Psychology, 91(2), 235-260. doi:10.1111/joop.12203

Kuhn, B., \& Demetrovics, Z. (2010). Emotional intelligence and addictions: A systematic review. Substance Use \& Misuse, 45(7-8), 1131-1160. doi:10.3109/10826080903567855

L'Abate, L., \& L'Abate, B. L. (1981). Marriage: The dream of the reality. Family Relations, 30(1), 131-136. doi:10.2307/584248
Magnusson, D., \& Cairns, R. B. (1996). Developmental science: Toward a unified framework. In R. B. Cairns, H. Elder, \& E. J. Costello (Eds.), Developmental science (pp. 7-30). New York, NY: Cambridge University Press.

Malinowska, D., Trzebińska, M., Tokarz, A., \& Kirkcaldy, B. (2013). Workaholism and psychosocial functioning: Individual, family and workplace perspectives. In C. Cooper \& A. S. Antoniou (Eds.), The psychology of the recession on the workplace (pp. 59-88). Cheltenham, UK-Northampton, MA: Edward Elgar.

Mazzetti, G., Schaufeli, W. B., \& Guglielmi, D. (2014). Are workaholics born or made? Relations of workaholism with person characteristics and overwork climate. International Journal of Stress Management, 21(3), 227-254. doi:10.1037/a0035700

Nathan, P. E. (1991). Substance use disorders in the DSM-IV. Journal of Abnormal Psychology, 100(3), 356-361. doi:10.1037/ 0021-843X.100.3.356

Oates, W. E. (1968). On being a "workaholic". Pastoral Psychology, 19(8), 16-20. doi:10.1007/BF01785472

Ployhart, R. E. (2008). The measurement and analysis of motivation: Looking past, moving forward. In R. Kanfer, G. Che, \& R. D. Pritchard (Eds.), Motivation: Past, present, and future (pp. 17-62). New York, NY: Lawrence Erlbaum Associates/ Psychology Press.

Raudenbush, S. W., \& Bryk, A. S. (2002). Hierarchical linear models: Applications and data analysis methods (2nd ed.). Thousand Oaks, CA: Sage Publications, Inc.

Reis, H. T., \& Gable, S. L. (2000). Event-sampling and other methods for studying everyday experience. In H. T. Reis, C. M. Judd, H. T. Reis, \& C. M. Judd (Eds.), Handbook of research methods in social and personality psychology (pp. 190-222). New York, NY: Cambridge University Press.

Robinson, B. E., \& Kelley, L. (1998). Adult children of workaholics: Self-concept, anxiety, depression, and locus of control. American Journal of Family Therapy, 26(3), 223-238. doi:10.1080/01926189808251102

Schaufeli, W. B., Taris, T. W., \& Bakker, A. B. (2008). It takes two to tango: Workaholism is working excessively and working compulsively. In R. J. Burke \& C. L. Cooper (Eds.), The long work hours culture: Causes, consequences and choices (pp. 203-226). Bingley, UK: Emerald.

Schuckit, M. A. (1994). DSM-IV: Was it worth all the fuss? Alcohol and Alcoholism, 2, 459-469.

Shimazu, A., Schaufeli, W. B., Kamiyama, K., \& Kamakami, N. (2015). Workaholism vs. work engagement: The two different predictors of future well-being and performance. International Journal of Behavioral Medicine, 22(1), 18-23. doi:10.1007/ s12529-014-9410-x

Sugisawa, A., \& Uehata, T. (1998). Onset of peptic ulcer and its relation to work-related factors and life events: A prospective study. Journal of Occupational Health, 40(1), 22-31. doi:10.1539/joh.40.22

Weber, M. (2005). The protestant ethic and the spirit of capitalism. London-New York: Routledge.

Worrall, L., Mather, K., \& Cooper, C. (2016). The changing nature of professional and managerial work: Issues and challenges from an empirical study of the UK. In A. Wilkinson, D. Hislop, \& C. Coupland (Eds.), Perspectives on contemporary professional work: Challenges and experiences (pp. 60-85). Cheltenham, UK: Edward Elgar. 